\title{
Um salto no escuro: experimentalidades entre corpo, arte e clínica na formação em psicologia
}

\author{
A leap in the dark: experiences between body, art and clinic in psychology \\ training
}

Adriana Rosa Cruz Santos; Catarina Resende; Clara Sym Cardoso de Souza Costa; Luiza Silva Loyola de Araújo; Maria Luiza de Carvalho Pardal Civiletti

Universidade Federal Fluminense

\begin{abstract}
RESUMO:
O estágio supervisionado na graduação em Psicologia é o plano de experimentação coletiva que emerge como aposta de formação na encruzilhada entre clínica e arte. Uma prática clínica transdisciplinar que se aproxima da arte de Hélio Oiticica como "forma de atividade" onde "possa emergir uma coletividade" por meio de apostas que propiciem "estados de invenção". Desse modo, afirmamos a dimensão estética da clínica por meio de dispositivos que engajem os estudantes na criação de si mesmos como terapeutas e na invenção de relações de cuidado singulares entre o próprio grupo e com os clientes. Tal direção nos aproxima de Foucault e suas proposições do cuidado de si e da estética da existência para tomar a formação do psicólogo como construção de um ethos. Arte, corpo e clínica se entrelaçam na constituição de uma experiência de formação que transita entre os planos intensivo e extensivo da existência e expressa os efeitos deste trânsito como criação de si, de objetos, de mundos ao experimentar ressonâncias, dissonâncias e partilhas.
\end{abstract}

Palavras-chave: formação; corpo; arte.

\begin{abstract}
:
The supervised internship in Psychology graduation is the collective experimentation plan that emerges as a training bet at the crossroads between clinic and art. A transdisciplinary clinical practice, approaching the art of Hélio Oiticica as a "form of activity" where "a collective may emerge" by means of bets that provide "states of invention". In this way, we affirm the aesthetic dimension of the clinic through devices that engage students in creating themselves as therapists and in inventing unique care relationships between the group itself and with clients. This direction brings us closer to Foucault and his propositions of self-care and the aesthetics of existence to take the psychologist's education as the construction of an ethos. Art, body and clinic are intertwined in the constitution of a training experience that transits between the intensive and extensive planes of existence and expresses the effects of this transit as the creation of oneself, of objects, of worlds when experiencing resonances, dissonances and sharing.
\end{abstract}

Key-words: development; body; art. 
DOI: 10.12957/mnemosine.2020.52683

A arte só pode ser um estado de invenção, só pode ser uma forma de experimentalidade, uma forma de atividade... O experimental é justamente a capacidade que as pessoas têm de inventar sem diluir, sem copiar, é a capacidade que a pessoa tem de entrar num estado de invenção, que é o experimental e ele tem a tendência de ser simultâneo, há vários níveis de experimentalidade, há tantos níveis de experimentalidade quantos indivíduos podem haver. A emergência do que Sartre chama de coletivo é exatamente essa capacidade que as pessoas têm em poder entrar no estado de invenção, de experimentar, a capacidade de experimental é o que pode fazer com que cada pessoa entre no estado de invenção e daí possa emergir uma coletividade (OITICICA, 2009/1979).

Compartilhamos a alegria de participar desta edição comemorativa aos 10 anos de formação inventiva de professores na Faculdade de Formação de Professores da UERJ e trazemos como contribuição um tanto de nossa experiência no processo de formação inventiva-inventante de psicólogas e psicólogos do Estágio em Psicologia Clínica no Serviço de Psicologia Aplicada (SPA) da Universidade Federal Fluminense (UFF). Inspiradas por Hélio Oiticica, apresentaremos neste ensaio "vários níveis de experimentalidade" desses processos formativos "em estados de invenção", compartilhados entre relatos de professoras-supervisoras e de alunas-estagiáriasextensionistas, criando uma narrativa difusa e intercambiante entre os atores na formação inventiva-inventante do psicólogo clínico. Nesta aposta a clínica se aproxima da arte de Oiticica como uma "forma de atividade", "uma capacidade de experimental", de onde "possa emergir uma coletividade".

Vamos elaborar aqui, indistintamente, alguns níveis de nossas experimentalidades tanto como coordenadoras quanto como estagiárias do projeto de Estágio Supervisionado Arte Corpo e Subjetividade, composto por duas propostas de formação simultâneas, que atuam de forma distinta e colaborativa: os projetos "Engenhos de vida: corpos, redes e territórios", coordenado por Adriana Rosa Cruz Santos e "Clínica, Corporeidade e transdisciplinaridade", coordenado por Catarina Mendes Resende. Ambos se articulam numa direção comum: a ativação da dimensão estética da clínica, por meio de dispositivos que engajem os estudantes na criação de si mesmos como terapeutas e na invenção de relações de cuidado singulares entre o próprio grupo de estagiários/extensionistas e na relação clínica com os clientes.

Tal direção nos aproxima também de Foucault ao tomar a formação como construção de um ethos, além de encontrar na arte uma importante aliada, visto que se trata na clínica, assim como na arte, de transitar entre os planos intensivo e extensivo da existência e expressar os efeitos deste trânsito como criação de si, de objetos, de 
mundos. Arte, corpo e clínica são transversais que se entrelaçam na constituição de uma experiência de formação que só é possível por meio de uma experimentação coletiva de entrelaçamentos, dissonâncias, ressonâncias, partilhas.

Neste escrito, Hélio Oiticica aparece como fio a provocar, apresentar e costurar eixos axiais que emergem em nosso processo de trabalho. Inspiradas na epígrafe que abre este escrito, propomos quatro eixos a partir dos quais apresentamos e discutimos nossa experiência de formação: 1) formação como construção de um ethos: cuidado de si e ativação de regime sensível; 2) como criar um corpo para o experimental ou procedimentos para uma formação inventiva; 3) o coletivo como plano de experimentalidades simultâneas, 4) salto no escuro: inventar sem diluir, sem copiar.

\section{Formação como construção de um ethos: cuidado de si e ativação do regime sensível}

A clínica na interface com a arte, enquanto prática de cuidado do outro, se faz necessariamente a partir do cuidado de si, numa relação estreita entre os processos de subjetivação e uma estética da existência. Tal articulação, inspirada pela problematização feita por Foucault acerca da História da Sexualidade, coloca em voga o tema do governo de si no tocante à constituição do sujeito nas suas relações consigo e com os outros, e o tema da conduta de vida deslocado das formas disciplinares.

Desse modo, o estágio em questão se propõe a levar o aluno a entrar em contato com dispositivos atuais que favoreçam a compreensão crítica e a experimentação daquilo que Foucault identificou como técnicas de si: "a arte de viver" deve ser conquistada dia após dia, durante toda a vida, num campo de atividades complexas, reguladas e cuidadosamente elaboradas (FOUCAULT, 1984a, 1984b). Nesta abordagem, o corpo passa a ser o instrumento operandis dessa ética pessoal enquanto prática de liberdade, e os processos terapêuticos são transversalizados pelos processos artísticos, por meio de dispositivos que potencializem a experiência estética e suas interferências na subjetividade e na corporeidade.

Nossos processos de formação em estados de invenção vêm fazendo composições entre as pesquisas desenvolvidas por cada docente, desdobrando-as numa experimentação clínico-política, capaz de entrelaçar experimentalidades simultâneas e coletivas entre arte-corpo-subjetividade-cidade. Aqui a expressão clínico-política deseja destacar o que muitas vezes fica invisibilizado num certo fazer clínico "tradicional", 
cujo foco seria a dimensão psíquica "individual”: que a clínica é indissociável do plano de produção da subjetividade, plano coletivo do viver. Se a subjetividade não se limita à "singularidade somática", para usar uma expressão de Foucault, ainda que nela se expresse, operar estratégias de cuidado num ambulatório-escola da universidade (o SPA) também não deveria se limitar ao "indivíduo" e seu suposto encapsulado "psiquismo". O cuidado pressupõe a análise das instituições (LOURAU, 1993) que constituem este equipamento (a psicologia, a formação, a universidade, a clínica, mas também a saúde mental, o SUS, a cidade, etc.), a ativação do que nas bordas da clínica a fazem derivar (a arte, a filosofia, a cidade, a política) numa articulação de redes de cuidado que desindividualizem o sofrimento daqueles que buscam atendimento e também dos agentes do cuidado.

Assim, não só tomamos aquele que chega em busca de atendimento como uma "singularidade somática" habitada por uma multiplicidade de intensidades e constituída por múltiplos agenciamentos, como também o estagiário-terapeuta se articula e se constitui numa rede que o sustenta e viabiliza a prática clínica.

A expressão rede abarca múltiplos sentidos. No campo da saúde mental, no âmbito do SUS, falar em rede é se reportar ao conjunto de equipamentos que configuram a oferta de serviços de saúde. Mas também pode significar o conjunto de pontos de sustentação na vida de uma pessoa: rede de sustentação psicossocial.

As redes são tecidas no território. Referimo-nos não apenas à dimensão geográfico-espacial, mas, sobretudo, à dimensão processual que articula os equipamentos da cidade aos sujeitos sociais concretos e seus modos de apropriação e circulação no/do espaço, que é, desde sempre, espaço em permanente engendramento, de acordo com as forças sociais em jogo a cada momento.

O território é a designação não apenas de uma área geográfica, mas das pessoas, das instituições, das redes e dos cenários nos quais se dão a vida comunitária. Assim, trabalhar no território não equivale a trabalhar na comunidade, mas a trabalhar com os componentes, saberes e forças concretas da comunidade que propõem soluções, apresentam demandas e que podem construir objetivos em comuns. Trabalhar no território significa resgatar os saberes e potencialidades dos recursos da comunidade, construindo coletivamente as soluções, a multiplicidade de trocas entre as pessoas, e os cuidados em saúde mental. (MINISTÉRIO DA SAÚDE, 2005)

As redes e os territórios também são imateriais: constituem-se de referências, saberes, memórias, pontos deflagradores de deslocamentos subjetivos e engendramento de novas possibilidades de estar no mundo, mas também de pontos de estagnação e 
circularidade mortífera. Redes densas, constituídas por corpos, afetos, sentidos, fazeres. Redes abertas à tessitura constante são, portanto, fundamentais na construção e sustentação de novos territórios subjetivos. Deligny (2015: 15) afirma que "a rede é um modo de ser", divergindo do paradigma moderno segundo o qual seria a razão o que caracterizaria o Humano e sinalizando que é num plano de múltiplos fios que se tece a vida e, sobretudo, a existência humana.

Assim, nossa aposta formativa na clínica pressupõe o deslocamento da esfera individualizante naturalizada (e permanentemente reinvestida) pelo capitalismo e a ativação de redes de cuidado, de sociabilidade, de subjetivação. Arte e cidade, portanto, não são dimensões incidentais na tessitura do cuidado, mas linhas fundamentais de afirmação do coletivo como plano de produção do viver e da dimensão estética, de criação, como o que permite que ensaiemos outras estilísticas da existência (FOUCAULT, 1984a, 1984b).

\title{
2. Como criar um corpo para o experimental ou procedimentos para uma formação inventiva
}

\begin{abstract}
A DESCOBERTA DO CORPO/ COMO ESTRUTURA SENSORIAL INEXPLORADA/ COMO MANANCIAL INALIENÁVEL Q CONDUZIRIA / À ESTRUTURAÇ̃̃O DO $Q$ CHAMO/ O NOVO/ COMO INVENÇÃO/ NÃO HÁ UM SEM O/ OUTRO/ A DESCOBERTA DO CORPO CONDUZIU/ À ESTRUTURAÇÃO DO NOVO [...]" (OITICICA, 2009: 184)
\end{abstract}

A tessitura dessas redes e territórios é de grande importância nesse fio de bordado entre arte-corpo-subjetividade-cidade. Proposições estéticas como a Estruturação do self, de Lygia Clark, ativam a sensorialidade corporal e ampliam o trânsito entre os estados intensivo e extensivo constitutivos do corpo, expressando a imanência corpo-subjetividade, arte-vida (MILLIET, 1992). Aqui damos destaque à Estruturação do self como procedimento simultaneamente artístico e clínico, já que a criação investe a própria estética da existência encarnada no corpo, produzindo processos de subjetivação.

O uso de objetos relacionais, proposto por Lygia na Estruturação do self e desdobrado por Lula Wanderley $(1996,2002)$ com pessoas psiquiatrizadas da rede pública de saúde, tem se revelado, há mais de três décadas, num potente dispositivo clínico que intervém no abismo entre afeto e palavra, por meio da ativação da memória corporal. Ali onde a palavra não se formou para dar passagem às dores que marcam o 
corpo, o objeto instaura possibilidades de expressão e reconstrução da memória corporal, abrindo no corpo e na vida espaço para a (re)criação de si mesmo e das relações com mundo (SANTOS, 2017; ROLNIK, 1996).

Instigadas pelos interstícios da clínica com a arte que essa proposição de Lygia Clark introduz, e apostando na cartografia do corpo sensível enquanto parte constituinte do processo formativo de estágio, quatro estagiárias se juntaram para se experimentarem em sessões de Estruturação do Self. O relato de uma delas traz sua experiência com alguns dos objetos, e suas reverberações:

"Em um de nossos encontros, foi colocado no meu busto, um objeto que não saberei nomear, por isso serei descritiva: eram o que suponho que fossem sementes, ou coquinhos secos, do tamanho mais ou menos de uma uva, amarrados aos pares em uma corda preta com uma altura de mais ou menos trinta ou quarenta centímetros. Era uma espécie de instrumento, parecia ter o propósito de fazer música. Mas ali estava no meu busto, encostando na dobra do meu pescoço que encontra o colo. Diferente do relato de $C$, não me lembro de nenhum outro objeto que tinha sobre mim, o colar-instrumento tomou todo o meu corpo. No momento mesmo em que foi disposto sobre mim, senti como uma pequena bola no encontro dos ossos que estruturam os ombros, onde se cria um vão na linha do nariz e do queixo. Senti uma bola ali dificultar minha deglutição, mas também me lembro que os outros objetos dos quais já não me lembro com precisão, ao serem colocados sobre meu corpo pareciam pesar de um modo que sentia o toque das mãos que os dispunham por um período longo.

Eu não saberia dizer de nenhuma outra sensação que não a daquela bola na parte final da minha garganta. Era como se toda a energia do meu corpo se condensasse ali e naquela dificuldade e incômodo que me causava, mas que parecia necessário e importante. Me deixei adentrar o incômodo, não sei se poderia dizer que não lutei contra ele de todo, mas o que sinto agora revisitando esse momento é que centralizei aquele ponto de energia que pulsava a partir do incômodo, e assim fiquei durante o tempo em que os objetos ficaram parados sobre meu corpo. No momento de retirada, quando para nos trazer ao presente formal, usávamos algum som, C tocou um pandeiro, e o colar-instrumento foi-me retirado do colo. Senti então uma espécie de falta de ar que não se bastava em quanto oxigênio eu pudesse inspirar, mas abri minha boca e curvei meu pescoço para trás no que hoje percebo ser uma tentativa de abrir meu peito ao ar que entrava. No instante do fato, meu corpo se mexia sem que eu tivesse muito controle cognitivo das ações, ainda que minhas funções motoras seguissem sendo possíveis enquanto comandos voluntários. Com peito e boca abertos, comecei a sentir todo o meu corpo pinicar, como se infinitas microagulhas me fossem enfiadas por toda parte, mas não era ruim. Dobrei minhas pernas, e minha mão segurava a pedra como uma garra, levando uma energia enorme para me segurar à pedra. Na outra mão que seguia livre, meus dedos ficaram rígidos e eu tentava movimentá-la sem muito sucesso. Minhas companheiras se assustaram e uma delas colocou a mão em minha cabeça, me acolhendo assustada. Eu queria falar para elas que estava tudo bem, que aquele era um estado novo e maravilhoso de experimentar meu corpo, que não se preocupassem, eu sentia toda energia necessária para pulsar nosso sangue pelo corpo, na superfície da epiderme. Eu vibrava, mas elas não sabiam, porque era impossivel falar naquele momento. 
Isso durou algum tempo entre segundos e horas, que é a eternidade. Eu não saberia precisar de forma alguma o momento em que comecei a sentir essa corrente de energia irradiar pelo meu corpo, ainda que consiga de alguma maneira ceder a tentativa de situar esse instante no tempo-espaço dos eventos. Mas a realidade é que o instante em que começou e terminou e o acontecimento em si não são demarcáveis nesse tempo e espaço formais, porque dizem de uma sensação atemporal." (CIVILETTI, 2019: 36-37)

Este relato nos lança numa ondulação entre Lygia Clark e Hélio Oiticica, pois a experiência da Estruturação do Self narrada nos permite mergulhar na gênese de um corpo para o experimental: "a descoberta do corpo" como "um manancial inalienável que conduziria" à invenção de uma "estrutura sensorial inexplorada". Se a invenção de um corpo singular "tem um quê" da invenção na arte, é possível neste fragmento visualizar nossa aposta formativa: arte e clínica são transversalizadas pela experiência estética numa perspectiva trandisciplinar, onde a arte aqui não é um fim, mas um meio para abrir o dispositivo clínico e os corpos dos participantes aos múltiplos fluxos que tecem a vida. A arte se apresenta como um campo de experimentação e de reencontro com a dimensão intensiva e inventiva do viver e a clínica é pensada à maneira da arte e com a arte. Unindo, em uma mesma experiência, a dimensão estética da produção do conhecimento à estética artística, abordaremos a arte como dispositivo para exprimir, criar e pensar o ser singular (GODINHO, 2007).

O exercício clínico transdisciplinar proposto será desnaturalizado enquanto um especialismo técnico-"psi”, alojado apenas em consultórios para atendimentos individuais, hospitais e outras organizações de saúde. A clínica se amplia pela sua capacidade de fazer conexões transversais que a potencializem enquanto experiência de abertura ao viver, favorecendo a criação de novas redes e a sustentação de territórios subjetivos ou, nos termos de Winnicott (1975), por experiências que nos tragam o "sentimento de que a vida vale a pena ser vivida".

O exercício de autoexperimentação proposto pelo grupo de estagiárias a partir da proposição de Lygia Clark com os objetos relacionais mantém acesa uma conversa que vai-e-vem com a epígrafe de Hélio Oiticica, que abre esta seção:

A DESCOBERTA DO CORPO/ COMO ESTRUTURA SENSORIAL INEXPLORADA/ COMO MANANCIAL ENALIENÁVEL Q CONDUZIRIA / À ESTRUTURAÇÃO DO Q CHAMOI O NOVO/ COMO INVENÇÃO/ NÃO HÁ UM SEM O/ OUTRO/ A DESCOBERTA DO CORPO CONDUZIU/ À ESTRUTURAÇÃO DO NOVO[...] (OITICICA, 2009:184) 
O exercício de autoexperimentação conjunta das estagiárias é um lançar-se compartilhado na direção do que ainda não existe, um mergulho de exploração e descoberta do corpo: não este visível, tangível, codificado pelas ciências da vida, mas o corpo misterioso e encantado que se desdobra daquele com suas marcas, seus cheiros, suas dobraduras inesperadas, sua cinestesia tresloucada pelo contato de objetos tão simples como um instrumento musical de coquinhos, uma pedra ou um saco d'água. Corpo encantado de afeto e memória, "estrutura sensorial inexplorada" (OITICICA, 2009) que é a matéria viva do fazer clínico. Como a fita de Moebius que Lygia Clark explora em Caminhando (MILLIET, 1992), o corpo do terapeuta se conecta ao corpo do cliente na invenção de uma relação de cuidado e abertura simultâneos. Aprender a ser psicólogo, portanto, é criar reciprocamente, como no fragmento do exercício relatado, um corpo para o experimental apoiado na dimensão coletiva do sensorial.

Nessa dimensão coletiva e simultânea do experimental, que faz corporeidades e temporalidades se cruzarem, podemos considerar ainda que a perspectiva transdisciplinar da clínica encontra ressonância na pedagogia das encruzilhadas, proposta por Rufino (2019). Nessa torção arte-clínica-pedagogia das encruzilhadas, o autor nos inspira a uma poética da multiplicidade, afirmando a diversidade como ethos existencial e motor das práticas educativas e o corpo como matéria sensível inventiva; na contramão das políticas cognitivas colonizadoras que operam a partir dos pressupostos de universalidade, uniformidade e racionalidade, como condição para a produção do conhecimento.

Nessa perspectiva, buscamos construir um dispositivo de formação transdisciplinar, na encruzilhada, no cruzo entre corpos, redes e territórios, pois "a pedagogia das encruzas é parida no entre [...]" (RUFINO, 2019: 73). Ser parida no entre significa afirmar a dimensão relacional do empreendimento pedagógico e, ousamos afirmar, da própria vida. Só existimos em relação com o fora de nós e é neste espaço entre corpos heterogêneos, na encruzilhada, portanto, que se produz o que ainda não existe. Que se inventa, que se cria, que se conhece, não por desvelamento da verdade supostamente entranhada na natureza, mas por movimentos de transfiguração e criação. Curiosamente, é também como encruzilhada que Foucault concebe o corpo:

Meu corpo está, de fato, sempre em outro lugar, ligado a todos os outros lugares do mundo, e, na verdade, está em outro lugar que não o mundo. Pois é em torno dele que as coisas estão dispostas, é em relação a ele - e em relação a ele como em relação a um soberano - que há uma acima, um abaixo, uma direita, uma esquerda, um diante, um atrás, um próximo, um longínquo. O corpo é o ponto zero do mundo, lá onde os 
caminhos e os espaços se cruzam, o corpo está em parte alguma: ele está no coração do mundo, este pequeno fulcro utópico, a partir do qual eu sonho, falo, avanço, imagino, percebo as coisas em seu lugar e também as nego pelo poder indefinido das utopias que imagino. O meu corpo é como a Cidade do Sol, não tem lugar, mas é dele que saem e se irradiam todos os lugares possíveis, reais ou utópicos. (FOUCAULT, 2013: 14)

Corpo-encruzilhada, "onde os caminhos e os espaços se cruzam", o corpo é, portanto, a (i)materialidade por meio da qual vivemos e construímos certa trajetória existencial. No entrelace com Foucault (2013), tomamos o corpo em sua acepção ampliada, corporeidade, como plano que encarna o pensamento, os regimes sensíveis, a materialidade orgânica, as políticas de subjetivação e que dá consistência existencial aos viventes que somos.

O corpo o qual estamos falando é corpo-organismo estudado no campo biológico, é corpo construído e representado simbolicamente; mas também é corpo que ao fazer a leitura, movimentou energias: entra em um ritmo, entrelaça os olhos, mergulha no vermelho do corpo e imprime movimentos intensivos. "Como experimentou a leitura do texto?" Um corpo que abdicou em saber a resposta, que recusa o óbvio, que se interessa no como, em sua expressividade. Faço abstenção em elaborar uma definição de corpo, pois corpo-escrita, corpo-clínico, corpo-intensivo, corpo-leitor, são formações corpóreas, são corporeidades. [...] De fato, abrir espaço ao intensivo é uma condição que demasiadamente requer reparação, mas se entendemos jogo como relação da relação, é esse trabalho clínico que nos propomos fazer, nos inclinando a permear nos espaços com o outro, reparar na qualidade do terreno - arenoso, aquoso, esponjoso - habitar com o outro esse terreno que já não o permite dançar, e juntos inventar um novo ritmo que esse corpo deseje ao encontrar o mundo. $O$ inventivo do corpo, perpassa pelo inventivo da vida, um processo mútuo de subjetivação e construção de mundo, em que cada indivíduo encontra na trajetória um contato com o fora através dos poros: com as coisas, com as pessoas, encontram forças que imprimem movimentos. Algumas dessas impressões duram mais tempo em seu estado de conservação, outras nem tanto, é a beleza de se perceber corpo em contágio, é como fazer amor com o mundo. (LOYOLA, 2019: 18)

É inconcebível, portanto, nessa perspectiva que afirmamos, propor ações de cuidado que não engajem globalmente o corpo em seus processos de transfiguração e expansão existencial.

O corpo é como o BRANCO NO BRANCO uma etapa-estado necessário para a chegada ao NOVO DIA DO INVENTOR. As experiências e a invocação experimental envolvendo o corpo sempre hão de aparecer e reaparecer de novos modos: tantos quantos seriam os indivíduos a experimentá-las. (OITICICA, 2009: 199)

Diferentes dispositivos são propostos nessa direção: encontros semanais entre as duas equipes, quando fazemos alguma experimentação a partir do que está emergindo no trabalho; circulação em espaços de arte, cultura e pensamento, etc. À exceção do 
encontro semanal, os demais dispositivos são móveis e acompanham os ritmos do grupo e dos acontecimentos na cidade ${ }^{1}$. Além das propostas envolvendo as duas equipes, cada uma tem seu próprio espaço de trabalho, onde são acompanhados os percursos clínicos desenvolvidos pelos estudantes-estagiários no SPA, que podem incluir atendimentos “individuais", grupais, oficinas, envolvendo não apenas a palavra, mas outros modos de expressão de si, construídos coletiva e singularmente em cada contexto, tal como apresentaremos a seguir.

\section{O coletivo como plano de experimentalidades simultâneas}

As proposições coletivas que engajam semanalmente os estagiários das duas equipes visam propiciar a constituição de um corpo capaz de criar dispositivos sintonizados com o que cada situação clínica exige, não se limitando ao tradicional formato psicoterápico que privilegia a expressão verbal, mas utilizando recursos corporais ampliados. Neste ponto, o projeto de estágio se articula aos projetos de pesquisa das supervisoras, que investigam, justamente, a relação corpo-subjetividade e a instauração de regimes sensíveis outros na formação do psicólogo (SANTOS, 2016; RESENDE, 2018).

Numa formação inventiva-inventante que convoca a corporeidade entre as noções de "cuidado de si" e de "corpo-encruzilhada", derivamos para uma das nossas direções de trabalho: o cuidado parte daquele que cuida de si para cuidar do outro, no cruzamento com esse(s) outro(s). A fim de visualizar alguns dos regimes sensíveis que emergem para um "cuidado coletivo de si", trazemos mais um relato intensivo de proposição corporal compartilhada entre as duas equipes do estágio:

Experimentação inspirada nos trabalhos da artista Lygia Clark e do artista e psiquiatra Lula Wanderley.

Era assim: algo como um túnel de plástico de uns três metros de extensão era sustentado por dez pessoas que se revezavam - quatro em cada lado de seu cumprimento, e uma em cada uma de suas pontas, sem fechar as passagens. De duas em duas, cada pessoa escolhia seu momento de entrar no túnel, depois de um tempo com os olhos já fechados pra que pudessem ser ativados outros sentidos. As entradas então aconteciam com cada uma entrando sempre através das opostas extremidades do túnel. Esses dois corpos percorriam esse túnel até saírem pelo lado oposto à sua entrada, de modo que a estreiteza do túnel não permitia que não acontecesse um encontro entre esses corpos, nesse percurso partilhado (...)

Foi mesmo como nascer, e logo se espreguiçar pra conhecer o entorno. Ele era composto de bordas-limites, como se uma incubadora me acolhesse em gestação. Olhos fechados e sensibilidade atentamente ativa, porque viva.

De repente se deu o encontro - incubadora partilhada.

Meus braços esticados pra trás deixaram que as pontas dos meus dedos tocassem as pontas dos cabelos de Barbarínea. 
Já pôde notar os efeitos gerados pelos mais sutis estímulos? Assim foi: efeito-convite às mãos de Barbarínea tocarem as minhas.

Desde o início não tínhamos pistas de como nos faria mover, aquele encontro. Imprevisível e inédito e singular são algumas palavras que têm me ajudado a significar, não só esse, mas os encontros todos.

Sim...

T O D O S os encontros são sementes em potencial de criação co-afetiva. A parte do nosso corpo que vibra e pede toque no contato com outro, ou a que repele e pede distância, não são mensuráveis ou classificáveis de forma pré-definida. Nem definitiva. Mas podem ser percebidas quando sentidas, e consentidas só se assim de desejo for, se o habitamos em sua dimensão intensiva.

Depois do toque-entre-mãos, umas fizeram força nas outras pros corpos se aproximarem, rastejantes no chão. Agora meu ouvido repousava no peito de Barbarínea. Pausa de alguns instantes pra sentir o sutil movimento que nascia, do pulso e do som de seu coração.

Movíamos e pausávamos em cada nova formação de corpo-estendido, fruto dos modos de abraçar que criávamos. Foi assim que seguimos, até o momento de despedida dos corpos, cada qual parido de volta pro mundo pela extremidade oposta de sua entrada na incubadora.

Grata por Barbarínea. Pelas relações de confiança nutridas com as pessoas queridas que sustentavam a germinação de nossa sintonia intensiva. Agradecida por caber tanto carinho e alento em nosso cuidadoso acolhimento. (COSTA, 2019: 66-67)

Mais uma vez, neste ensaio, trazemos uma narrativa que revela a gênese de "estruturas sensoriais inexploradas", e que dá relevo ao coletivo como plano de experimentalidades que tendem ao simultâneo para a descoberta do corpo, como diria Oiticica. A estagiária relata um plano-sequência de experimentações no encontro consigo mesma e com o outro, sustentadas por uma grupalidade entorno-contorno que nomeia de "incubadora partilhada". No coletivo foram criadas as condições de sustentação para a "germinação" de um "percurso partilhado" em que os mais sutis dos estímulos pudessem ter a consistência de encontros, cruzamentos, gestações, nascimentos, enfim, "sementes em potencial de criação co-afetiva".

É neste sentido que nos engajamos na construção de momentos em grupo que favoreçam vivências de coletivização e mutualidade: numa articulação intercambiante entre formação e cuidado, as descobertas do corpo e de regimes sensíveis outros acontecem em experiências de reciprocidade e confiança. Assim, as experimentalidades, mesmo tendendo ao simultâneo, mantém as assimetrias dinâmicas entre temporalidades que coincidem e se defasam, considerando a dimensão sempre singular dos processos de subjetivação e da criação de sentidos para o vivido.

Partindo de proposições estéticas, tal como a acima relatada, desejamos construir dispositivos que propiciem o encontro entre diferenças humanas e não-humanas (como o "colar-chocalho", o "túnel de plástico-incubadora"), a abertura de canais de expressão 
de virtualidades subjetivas, a expansão de redes de cuidado e a construção de territórios existenciais conectados ao movimento incessante da vida na cidade e na sensorialidade do corpo. Propomos construir estratégias que envolvam também a cidade na produção de sentidos e modos de subjetivação coletivos, capazes de responder ao desafio que é viver numa metrópole de patrimônio étnico e cultural diversificado, atravessada por intensas desigualdades socioeconômicas, sem reduzir o sofrimento daí advindo à esfera do sintoma individualizado/ individualizante.

Dentre as estratégias de extrapolar os muros da Universidade, de envolver a cidade e a arte em nossas produções de cuidado, criação de sentido e de modos de subjetivação coletivos, integrantes das duas equipes de estágio foram juntxs até Inhotim, Instituto de Arte Contemporânea localizado em Brumadinho, Minas Gerais. Esta imersão nos proporcionou encontros não só com as muitas instalações artísticas, mas com os percursos entre-instalações, conforme incorporávamos inusitadas conformações com bancos-troncos-túneis, plantas, flores e raízes suspensas. Fundíamo-nos e saíamos outros.

O relato a seguir convida a uma perspectiva do que foi experimentado em uma dessas instalações de arte contemporânea:

Nessa instalação - Sonic Pavilion, concebida por Doug Aitken - éramos convidados a escutar. $O$ som do fundo da terra. Captado ao vivo, sem roteiro prévio, nem hora marcada pra repetição, por microfones a 200 metros de profundidade do solo.

Difícil expressar os efeitos dessa escuta no corpo, viu?

Urros e sussurros, descontrolados, imprevisiveis, compõem as entranhas intraterrestres. Como se entoassem um canto profundo e denso. Me fizeram sentir os movimentos, sonoros e viscerais, ininterruptos enquanto pulso, dos interiores que me habitam. Misteriosos, como o ventre da mãe terra, em constante e resistente gestação de vida.

Não sei precisar por quanto tempo estive imersa nessa experiência, mas sei dizer que ela deu outro estado pro meu corpo. Os passos que o conduziram por entre matos e encantos até a próxima instalação, foram percebidos por ouvidos mais sensíveis, mais afetuosos aos arredores. Às folhas das árvores que faziam música com o vento.

O som é um dos meios de expressão do mundo. Da terra, do universo. De nós também. Nosso corpo tem potência de perceber - não esquecer (!)" (COSTA, 2018)

A relevância de incluir esse tipo de relato aqui tem a ver com isso: embora teorias, conceitos e técnicas sejam importantes ferramentas de trabalho - sobre as quais nos debruçamos com rigor -, elas se mostram insuficientes se o intuito é aproximar-se da abertura de sentido, sempre singular, que um sujeito (diferente de si) estabelece com suas vivências e entornos. Para que se trate de aproximações éticas, que, portanto, desviam do lugar dominador de suposto saber teórico para encarnar presenças, o que 
afirmamos é que importa que sejam possibilitadas, aos corpos viventes, condições de acesso às suas dimensões intensivas. Aquelas que permitem ativar o que é da ordem da capacidade vital de afetar e ser afetado (SPINOZA, 2007), capacidade interconectada com experiências de ensino-aprendizagem auto-responsáveis e libertárias.

Considerando o que conecta clínica, educação e vida, nos engajamos na cocriação de um processo de formação que sensibiliza para a relevância de, mais que respeitar, valorizar os aprendizados que cada vida, cada corpo, tradicionalmente escolarizado ou não, se põe a experimentar com sua dimensão intensiva no encontro com o mundo.

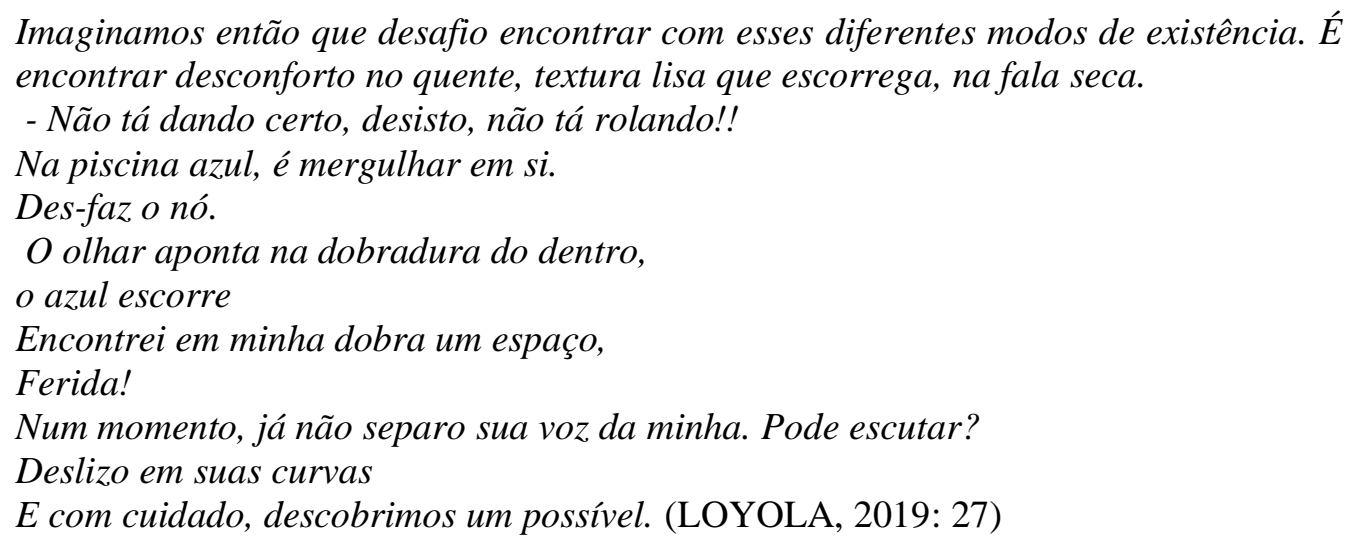

Essa passagem foi construída por outra estagiária, tendo como disparador a instalação Cosmococa de Hélio Oiticica, no mesmo "trabalho de campo" em Inhotim. Assim nomeamos nossa viagem, pois os mais sutis dos estímulos ganhavam a consistência de trabalho ao caminharmos na imensidão do museu a céu aberto. Ao fazer a leitura, nos surpreende, em um primeiro momento, a dificuldade de circunscrever o poema apenas na objetividade da experiência: ir ao museu. Como ela mesma questiona: "É difícil definir sobre o que diz o poema: Trabalho de campo? Grupo terapêutico? Atendimento individual? Supervisão? Minhas relações?”.

A proposta que fazemos inevitavelmente acontece. A partir do poema que sustenta viva nossa conversa com Oiticica, torna-se possível perceber que nas relações intercambiantes atender - ser atendido, ensinar - aprender, estar no mundo - ser o mundo, os processos de subjetivação se desenrolam em diferentes níveis de experimentalidades que tendem ao simultâneo em "dobraduras" dentro-fora, eu-outro incessantes.

\section{Salto no escuro: inventar sem diluir, sem copiar}


De sobressalto, uma ressalva: antes mesmo que a perspectiva aqui apresentada ganhe estatuto de proposta pedagógica para a formação em psicologia, consideramos que seja uma dinâmica que já acontece, inerente ao viver. Então, por que, ainda assim, defendê-la como direção formativa? Porque, se consideramos isso por um lado, por outro reconhecemos que se pode passar uma vida inteira sem ser afetado por esses regimes sensíveis germinados pela descoberta de novos modos de existência. Alguns artistas, como Hélio Oiticica e Lygia Clark, têm nos mostrado que esse é um exercício próprio da arte: a invenção do novo é inalienável da descoberta do corpo. Acreditamos que cabe a nós, também na formação clínica, nos dedicarmos a reparar e atuar nessas relações sutis. Inspiradas por Oiticica, interessa-nos exercitar nossa sensibilidade durante a formação para que possamos perceber o "BRANCO NO BRANCO" do corpo não como um igual a si mesmo, mas sim como um modo de exprimir "uma etapa-estado necessário para a chegada ao NOVO DIA DO INVENTOR”.

E para uma etapa-estado inventor, Oiticica assinala que "o experimental é justamente a capacidade que as pessoas têm de inventar sem diluir, sem copiar, é a capacidade que a pessoa tem de entrar num estado de invenção (...)" (OITICICA, 2009). Retomando esse trecho da epígrafe que abre nossa escrita, sublinhamos: na transversalidade entre formação-clínica-arte investimos naquilo que pode ser inventado "sem diluir, sem copiar", isto é, apostamos na gênese de regimes sensíveis que possam trazer consistência ao corpo em experiências inaugurais. Essa atitude exige prudência e rigor compartilhados por todos os envolvidos, por reconhecer que num grupo em formação "há tantos níveis de experimentalidade quantos indivíduos podem haver" (OITICICA, 2009).

Propomo-nos então, dialogando com Oiticica e Foucault, a destinar um lugar de trabalho e cuidado recíprocos na constante análise de nossas práticas. Se os processos de subjetivação são tecidos num entrecruzamento incessante entre o singular e o coletivo, apostamos nessa experiência processual e intersticial de uma formação inventivainventante, com a intenção de compor os saberes e não a mera replicação deles.

Assim como inventou Hélio Oiticica (2009), inventamos nossa própria "deriva experimental" ou "delírio ambulatório". No caso de Hélio tratava-se de deambular de forma errante pela cidade, colocando-se numa experiência de abertura ao acontecimento. No nosso também. Mais especificamente, trata-se de fazer delirar o ambulatório do serviço de psicologia aplicada (SPA), um dos espaços de formação em 
clínica do curso de psicologia da UFF, de modo a abri-lo para as variações cotidianas que o interpelam, a expansão universitária e suas agruras, o contexto socioeconômico precarizado-precarizante e os sofrimentos daí decorrentes, as políticas de subjetivação capitalísticas, aplainadoras de toda experiência à lógica do consumo descartável. Passamos a escutar vozes. Múltiplas. Da coordenação do ambulatório-escola, que sinalizava um aumento significativo da procura de estudantes da própria universidade por psicoterapia no SPA, o que estava ocasionando um congestionamento na porta de entrada do serviço e demandando alguma proposta; vozes dos estagiários que se sentiam movidos a ensaiar uma experiência coletiva de cuidado de si e de outros; as vozes que gritam em nós por um tanto de possível, de ensaiar formas de viver coletivas, vigorosas e belas.

As apreensões, as dúvidas quanto aos próprios recursos de "manejo" das situações grupais e tantas outras ainda não inventadas ou anteriormente prescritas, o frio na barriga antes do salto rumo ao desconhecido... Decidimos, então, inventar modos de ensaiar o salto, ainda que soubéssemos ser impossível apreendê-lo na sua radical singularidade. "Brincar de saltar" poderia ajudar a afastar o tanto de fantasmas que criamos em torno da expectativa de saltar, poderia desfazer o medo paralisante e ajudar a construir uma musculatura afetiva (ARTAUD, 1987/1938) que desse sustentação a este e a tantos outros saltos no desconhecido que temos que fazer na vida e na clínica. Tais estratégias são muitas vezes propostas no calor do acontecimento grupal, emergem como possibilidade de dar corpo às intensidades dispersas e cuidar das fantasias produzidas pelo imaginário tecnicizado e onipotente do terapeuta em formação.

A partir daí abrimos passagem para falar do que engasga: do medo de não funcionar, da nossa incerteza diante a aposta nos grupos enquanto dispositivo de cuidado; da formação clínica ainda marcadamente individualizante e reduzida ao formato clássico da psicoterapia individual. Abrimos passagem para partilhar nossas dúvidas, inseguranças e apostas como ideias e gestos que se iluminam na sombra: aprender que a criação é um salto no escuro. Inventar o que ainda não existe é, em certa medida, da ordem do delírio, da criação de outra realidade. E quando criamos outra realidade, ainda que de pequenas dimensões, necessariamente nos recriamos, nos fazemos outros de nós. E tal operação implica numa absoluta ignorância, pois o que será ainda está por se fazer, na contingência única do acontecimento. Mas aprendemos também que o acontecimento e o salto são sempre constituídos por muitos fios, nem 
todos visíveis. $\mathrm{O}$ acontecimento é sempre coletivo e implode a arrogância da autoria ${ }^{2}$. Num salto cabem sempre muitos mundos, um salto inaugura outros usos de si e de tudo que o cerca.

\section{Referências}

ARTAUD, Antonin. Um Atletismo afetivo. EM: ARTAUD, Antonin. O teatro e seu duplo. São Paulo: Ed. Max Limonad, 1987/1938.

CIVILETTI, Maria Luiza C. P. Estrutura-se um corpo-psicóloga: a estruturação do self no cuidado com o feminino, 2019. Monografia de Conclusão de Curso. Instituto de Psicologia. Universidade Federal Fluminense. Niterói, 2019.

COSTA, Clara.S.C.S. Relatório de Estágio. Instituto de Psicologia. Universidade Federal Fluminense. Niterói, 2018.

COSTA, Clara.S.C.S. Entre cartas, não-monogamia e micropolítica afetiva das relações: a liberdade como prática de cuidado ao amor. Monografia de Conclusão de Curso. Instituto de Psicologia. Universidade Federal Fluminense. Niterói, 2019.

DELIGNY, Fernand. O aracniano e outros textos. São Paulo: n-1 Edições, 2015.

FOUCAULT, Michel. O que é um autor? EM: MOTTA, M. B. (org.) Estética: literatura e pintura, música e cinema. Coleção Ditos e escritos, v. 3. Rio de Janeiro: Forense Universitária, 2001.

FOUCAULT, Michel. O corpo utópico, as heterotopias. São Paulo: n-1 Edições, 2013.

FOUCAULT, Michel. A Ética do Cuidado de Si como Prática da Liberdade (1984a). EM: MOTTA, M. B. da (org.) Ética, Sexualidade, Política: Michel Foucault. Rio de Janeiro: Forense Universitária, 2004. Coleção Ditos \& Escritos, v. V.

FOUCAULT, Michel. Uma Estética da Existência (1984b). EM: MOTTA, M. B. da (org.) Ética, Sexualidade, Política: Michel Foucault. Rio de Janeiro: Forense Universitária, 2004. Coleção Ditos \& Escritos, v. V.

GODINHO, Ana. Linhas de estilo: estética e ontologia em Gilles Deleuze. Lisboa: Relógio D’Água, 2007.

LOYOLA, Luiza. O contato do clínico com o corpo intensivo para habitar na clínica o "sentir com", 2019. Monografia de Conclusão de Curso. Instituto de Psicologia. Universidade Federal Fluminense. Niterói, 2019.

LOURAU, René. René Lourau na UERJ - Análise Institucional e Práticas de Pesquisa. Rio de Janeiro: UERJ, 1993.

MINISTÉRIO DA SAÚDE. Secretaria de Atenção à Saúde.DAPE. Coordenação Geral de Saúde Mental. Reforma psiquiátrica e política de saúde mental no Brasil. Documento apresentado à Conferência Regional de Reforma dos Serviços de Saúde Mental: 15 anos depois de Caracas. OPAS. Brasília, novembro de 2005.

MILLIET, Maria Alice. Lygia-Clark: obra-trajeto. São Paulo: EdUSP, 1992. 
OITICICA, Hélio. Hélio Oiticica. Organização Cesar Oiticica Filho e Ingrid Vieira. Rio de Janeiro: Beco do Azougue, 2009.

RESENDE, Catarina. Uma arte das conexões sutis: a formação de um corpo-clínico sensivel. Projeto de pesquisa. Instituto de Psicologia. Universidade Federal Fluminense. Niterói: 2018.

ROLNIK, Suely. Lygia Clark e o híbrido arte/clínica. EM: COSTA, M. S. R. et al. Pontos de fuga: visão, tato e outros pedaços. Rio de Janeiro: Taurus, 1996.

RUFINO, Luiz. Pedagogia das encruzilhadas. Rio de Janeiro: Mórula Editoria, 2019.

SANTOS, Adriana Rosa C. Memória da pele, membrana da alma: corpo, subjetividade e pensamento. Projeto de pesquisa. Instituto de Psicologia. Universidade Federal Fluminense. Niterói: 2016.

SANTOS, Adriana Rosa C. Verbo revertido ao ventre: criar, encorpar, enlouquecer. EM: RODRIGUES, H. B. C.; COSTA. M. J. A. (orgs.) Foucault e os modos de vida. São Luís: EDUFMA, 2017.

SPINOZA, Benedictus de. Ética. Belo Horizonte: Autêntica Editora, 2007.

WANDERLEY, Lula. O vazio vivo. EM: PITTA, A. (org.) Reabilitação psicossocial no Brasil. São Paulo: HUCITEC, 1996.

WANDERLEY, Lula. O dragão pousou no espaço: arte contemporânea, sofrimento psíquico e o objeto relacional de Lygia Clark. Rio de Janeiro: Rocco, 2002.

WINNICOTT, Donald. W. O brincar e a realidade. Rio de Janeiro: Imago, 1975.

Adriana Rosa Cruz Santos

Universidade Federal Fluminense

E-mail: arosacs@uol.com.br

Catarina Resende

Universidade Federal Fluminense

E-mail: catarinamresende@gmail.com

Clara Sym Cardoso de Souza Costa

Universidade Federal Fluminense

E-mail: clarasym@hotmail.com

Luiza Silva Loyola de Araújo Universidade Federal Fluminense E-mail: luizasloyola@gmail.com

Maria Luiza de Carvalho Pardal Civiletti Universidade Federal Fluminense E-mail: maluciviletti@gmail.com

\footnotetext{
1 A esse respeito, cabe referir a parceria com o Laboratório Kumã, do Curso de Cinema/UFF, na construção de um dispositivo de produção de imagem, que engajou estagiários da Psicologia, do Cinema e clientes do SPA, numa proposição híbrida entre o cinema e a clínica, visto que o trabalho com a imagem também engaja a produção de outros olhares sobre si e sobre o mundo, apresentando efeitos-subjetivação.
} 


\footnotetext{
2 Em ressonância à problematização que Foucault (2001) empreende sobre a função-autor em nossa cultura e a partilha entre quem tem e quem não tem legitimidade para produzir e fazer circular enunciados, valorizamos a proposta de estarmos, supervisoras e estagiárias, diluídas em nossas ideiasrelatos-narrativas aqui apresentadas, povoadas por muito mais vozes do que as referidas nessas cinco que assinam o artigo, em mais um gesto que reafirma nossa aposta no coletivo e na polifonia dos processos de ensino-aprendizado.
} 